\title{
The Great Resignation: An Argument for Hybrid Leadership
}

\author{
Dr. Joseph C. Hopkins and Dr. Kimberly A. Figaro \\ College of Business, Dallas Baptist University, Dallas, Texas U.S.A \\ *Correspondence: Dr. Kimberly A. Figaro, kfigaro@dbu.edu
}

\begin{abstract}
The purpose of this article is to contribute to past research conducted as it relates to the leadership competencies and attributes promoting social interaction that influence employee retention in virtual and hybrid work environments. A quantitative study involving 304 workers across a diverse group of industries, divided amongst face-to-face, hybrid, and virtual work environments suggested that social interaction was a significant predictor of job embeddedness in hybrid $(\beta=.15, t(96)=2.16, p<.05$ and virtual $(\beta=.33, t(86)=7.96, p<.05)$ work groups. Additional research is needed to identify the leadership competencies and attributes that promote social interaction amongst team members in both virtual and hybrid environments. Several instruments are needed. Firstly, a measure for the Knowledge, Skills, and Abilities (KSAs) of hybrid and virtual team leaders. Secondly, an instrument to assess social interaction amongst hybrid and virtual team members. Finally, a modification to the Mitchell et al.'s embeddedness instrument to incorporate Work From Home (WFH) and Work From Away (WFA) environments.
\end{abstract}

KEYWORDS: Hybrid, Leadership, Remote work, Social interaction, Virtual teams

\section{ARTICLE INFORMATION}

Author(s): Dr. Joseph C. Hopkins and Dr. Kimberly A. Figaro

Received: 30 Aug, 2021; Accepted: 05 Oct, 2021; Published: 30 Oct, 2021; e-ISSN: 2347-4696;

Paper Id: BMN-IJBMR-2021-67;

Citation: doi.org/10.37391/IJBMR.090402

Webpage-link:

https://ijbmr.forexjournal.co.in/archive/volume-9/ijbmr-090402.html

\section{INTRODUCTION}

During the years 2018 and 2019, the United States (U.S.) experienced record employment, which led to an increase in employee resignations [1]. Jobs were plentiful and workers were willing to leave for higher pay and benefits. In 2020, as the coronavirus pandemic continued, unemployment escalated to almost $15 \%$ [2]. Resignations plummeted as workers faced a gloomy job market and the need for employer-based health insurance increased, keeping many dissatisfied workers in place $[1,2]$.

For decades, scholars and business leaders have debated the ability of organizations to drive productivity and innovation through remote work models. This debate escalated when the pandemic forced millions of workers to uproot their face-toface work environment and set up office in their homes. The Bureau of Labor Statistics suggested 35\% of Americans, a 2020 pandemic peak, worked remotely [2]. The great remote work experiment demonstrated that worker productivity increased in remote work models [2, 3]. Companies like Facebook announced remote work would remain permanent post pandemic. In early 2021, as more people received the coronavirus vaccine, infection rates began to decrease, many began to believe the pandemic was over. Companies such as ExxonMobil, Morgan Stanley, and Goldman Sachs implemented plans to bring workers back into the office [4].

With over a year of lockdowns and isolation, workers took the opportunity to re-evaluate their lives and priorities [1]. After experiencing 12 to 18 months of newfound freedoms, many were no longer willing to settle for a nine-to-five job saddled with commute times and expenses, along with inflexible schedules and inflexible leaders. Workers refused to revert to the pre-pandemic in-person workplace and focused on a future centered on personal and family needs [5]. Anthony Klotz, Associate Professor at Texas A\&M University, coined the term, The Great Resignation, predicting a post pandemic surge in employee resignations $[1,6]$. Supporting Klotz's prediction, a March 2021 Gallup poll suggested that $48 \%$ of U.S. workers, from all job categories, were not engaged or actively disengaged leading to 3.6 million resignations in the month of May, 2021 alone [7]. Klotz [1] suggested the pent-up demand for change will only escalate as the 2021-year progresses. Organizations not willing to provide flexible, fully remote or hybrid work schedules will face higher levels of resignations [5].

MIT researcher, Ben Waber, acknowledged the short-term productivity gains from the pandemic forced WFH strategy, but predicted a one-to-two-year degradation of company culture, productivity, and innovation [3]. Analyzing current client communication data, Waber found that colleagues with strong relational ties, working face-to-face or remote, spent $45 \%$ of their time communicating [3]. Weeks into the pandemic with many working remotely, the communication between individuals with strong ties exceeded 60\% [3]. Colleagues with weaker ties, those who communicated less than 15 minutes per week, dropped by 30\% [3]. Waber contended the vast majority of creative ideas originated through casual, accidental communication between those with weaker ties [3]. In the short-term, Thompson [3] suggested that organizations will continue to meet key performance objectives, but a general degradation of organizational health and performance will linger on the horizon.

Remote work is just one of many challenges leaders face in the

The Great Resignation: An Argument for Hybrid Leadership 
current complex environment. Research into leadership competencies and attributes suggested leaders in remote work settings require higher KSAs than their face-to-face counterparts [8]. As organizations continue to integrate remote work settings, there is a need to develop leadership KSAs to support the complex environment of remote and hybrid work environments.

\section{LITERATURE REVIEW}

\subsection{The Virtual Workforce}

The ability to work virtually is quintessential in the $21 \mathrm{st}$ century global environment [8, 9]. Technological advancements have provided a platform for diverse cultural teams to span cities as well as continents. What was previously a strategy aimed at reducing energy costs, traffic congestion, and toxins in the environment, has in many ways now become the platform for policy regarding many organizations' Continuity of Operations (COOP) [8]. Fueled by the tragic events of September 11, 2001, at the World Trade Center in New York City and the Pentagon, many organizations, including the U.S. government developed a strategy to continue operating should another catastrophic event occur [10].

The virtual workforce can be defined as having little or no face-to-face interaction with colleagues and depending primarily on technology-mediated tools for communication [8, 11]. Because the pandemic forced organizations to send their workforce home, those who typically worked in face-to-face office environments were catapulted into virtual settings. Hence, the term work from home (WFH) was coined. Conversations relative to "how to manage performance when people cannot be seen" were largely the reason why the Telework Act of 2003 was not fully implemented until well after 2011 [8]. Spanning almost two decades, the WFH debate has become even more amplified, in that the pandemic reignited an era of digital transformation and broadened the use of collaborative technology in and out of the workplace which, in essence, has shifted the focus from the employee to the leader and organization.

While organizations have scrambled to reinvent themselves amid a pandemic, the debate continues. Many are still not clear if the WFH model and which WFH model best suits their organizational goals and if they will return to the physical workplace at all [12]. In effect, the WFH model has become one solution, but not the solution to the decade's old question of how to lead people when they cannot be seen. Recent research suggests that $75 \%$ of the workforce polled would prefer WFH arrangements with preferences ranging from one to five days per week [12]. Now that the pandora's box of working arrangements has been opened, it may be a mistake for organizations to assume that workers will be content to return to a pre-pandemic work state. In fact, the great resignation suggests otherwise and so the argument leaning heavily towards the hybrid environment and the need for leaders who can lead a hybrid workforce ensues.

\subsection{The Hybrid Workforce}

Hybrid workplaces consist of blending highly flexible environments, incorporating the traditional in-office, physical face-to-face with remote work settings where workers flex in and out of the office, with a heavy reliance on technologymediated communication [13-15]. While hybrid models are not new, they have gained popularity as companies prepare a post-pandemic workplace. Organizational leaders grapple with challenges of combining workers who have grown accustomed to working from home with the face-to-face component of their existing work environment. Leaders are beginning to realize that varying worker needs requires a hybrid work model that is fluid and flexible [13]. Some workers demand fully remote, while others desire a combination of remote and face-to-face. Some workers fear a lack of face-to-face engagement with leadership will hamper promotion and advancement.

Figaro's [8] research suggested effective leadership in remote work settings require higher leadership KSA levels. The hybrid workforce requires leaders who can effectively lead in face-to-face and remote settings, with a unique ability to bring the two environments into a cohesive unit.

\subsection{Job Embeddedness}

Early employee turnover research sought to understand why employees chose to leave an organization [16, 17]. In 2001, Mitchell et al. created a shift in the research of employee turnover with a new turnover construct, job embeddedness. Mitchell et al. [16] described job embeddedness as a "net or web in which an individual can become stuck." Highly embedded workers develop an array of ties that linked them to the organization which, can be likened to organizational commitment [16]. The primary distinction between the embeddedness construct and other worker turnover research, is the understanding that discernable connections exist on-thejob as well as off-the-job [16]. Normative pressures to remain with an organization go beyond the job and organizational satisfaction to include family, community, hobbies, and outside interests $[16,18]$.

\subsection{Social Interaction}

Pentland [19] and Waber [20], MIT researchers, have conducted extensive research on workplace social interaction, collaboration that promotes empathy and building trusting relationships. Their research concluded that impromptu conversations, where workers interact in a non-formal setting, nurtures personal relationships through increased empathy and trust. The improved relationships yield higher productivity, creativity, and innovation [19-21]. Pentland [19] and Waber [20] contended face-to-face interactions are foundational to building empathy and trust, which are crucial to engagement, creativity, and innovation.

\section{METHODOLOGY}

A study conducted by Hopkins [22] sought to 1) determine if there were relationships between leadership competencies and attributes, social interaction, and job embeddedness across the 
three work groups, face-to-face, hybrid, and remote, 2) determine if there were differences between the three groups in relation to leadership competencies and attributes, social interaction, and job embeddedness and 3) to determine if leadership competencies and attributes along with social interaction were significant predictors of job embeddedness.

The study employed a quantitative design that explored the relationships between leadership competencies and attributes among team leaders, team member social interaction, and job embeddedness in virtual environments [22]. Participants were drawn from diverse business sectors ranging from education, not-for-profit, petrochemical, supply chain, technology, telecom, and transportation. All were 18 years of age or older and worked within their current team for a minimum of six months. The population included team members from three separate groups: face-to-face, hybrid, and virtual environments. Participants responded to an anonymous survey that included questions drawn from validated leadership, social interaction, and job embeddedness instruments. A total of 350 responses were received, of which, 304 were complete and valid [22]. Seven questions guided this study:

Research Question 1 (RQ1) are there relationships between leadership competencies and attributes and social interactions across all groups; co-located, mixed, and virtual?

Research Question 2 (RQ2) is there a relationship between social interaction and job embeddedness across all groups; colocated, mixed, and virtual?

Research Question 3 (RQ3) are there relationships between leadership competencies and attributes and team member job embeddedness across all groups; co-located, mixed, and virtual?

Research Question 4 (RQ4) are there differences between teams working in co-located environments, mixed environments, and virtual environments in relation to leadership competencies and attributes?

Research Question 5 (RQ5) are there differences between teams working in co-located environments, mixed environments, and virtual environments in relation to social interactions?

Research Question 6 (RQ6) are there differences between teams working in co-located environments, mixed environments, and virtual environments in relation to team member job embeddedness?

Research Question 7 (RQ7) when taken together, which of the leadership competencies and attributes along with social interaction, are the most significant predictors of Job Embeddedness?

A correlational analysis examined the relationships between the three groups [22]. Cohen [23] suggested a minimum sample size of 85 participants per group at alpha $=.05$, power $=$ .80 and medium effect size. A series of ANOVAs examined the differences between the groups. ANOVAs with an alpha = .05 , power $=.80$, and medium effect size, require a minimum sample size of 52 per group [23]. A reverse stepwise regression was used to determine if leadership competencies and attributes along with social interaction were significant predictors of job embeddedness [22]. Reverse stepwise regression analysis at alpha $=.05$, power $=.80$ and medium effect size require 40 samples per independent variable [24, 25]. The survey responses included 115 in the face-to-face group, 101 in the hybrid group, and 88 in the virtual group, exceeding the minimum requirements for each analysis [22].

\section{RESULTS}

RQ1, RQ2, and RQ3 examined the relationships between leadership competencies and attributes, social interaction, and job embeddedness. RQ1 asked if there was a relationship between social interaction and the leadership competencies and attributes. Twelve hypotheses were tested using a Pearson $\mathrm{r}$ correlational analysis. The results are displayed in Table 1. The findings suggested a significant positive relationship between social interaction, self-awareness, relational transparency, internal moral perspective, and balanced processing across each of the three groups [22].

\begin{tabular}{|l|c|c|c|c|c|c|}
\hline & \multicolumn{2}{|c|}{ Face-to Face } & \multicolumn{2}{c|}{ Hybrid } & \multicolumn{2}{c|}{ Virtual } \\
\hline & $\boldsymbol{r}$ & rho & $\boldsymbol{r}$ & rho & $\boldsymbol{r}$ & rho \\
\hline $\begin{array}{l}\text { Self- } \\
\text { Awareness }\end{array}$ & $.814^{* *}$ & $.802^{* *}$ & $.770^{* *}$ & $.780^{* *}$ & $.822^{* *}$ & $.753^{* *}$ \\
\hline $\begin{array}{l}\text { Relational } \\
\text { Transparency }\end{array}$ & $.804^{* *}$ & $.723^{* *}$ & $.681^{* *}$ & $.682^{* *}$ & $.812^{* *}$ & $.768^{* *}$ \\
\hline $\begin{array}{l}\text { Internal } \\
\text { Moral } \\
\text { Perspective }\end{array}$ & $.682^{* *}$ & $.665^{* *}$ & $.696^{* *}$ & $.633^{* *}$ & $.837^{* *}$ & $.745^{* *}$ \\
\hline $\begin{array}{l}\text { Balanced } \\
\text { Processing }\end{array}$ & $.802^{* *}$ & $.777^{* *}$ & $.725^{* *}$ & $.723^{* *}$ & $.797^{* *}$ & $.743^{* *}$ \\
\hline $\begin{array}{l}\text { Notes: ** Correlation is significant at } .01(2 \text { tailed); df }=302 \text {; Face-to-Face - } \\
\text { N=115, Hybrid - N = 101, Virtual - N = 88. }\end{array}$ \\
\hline
\end{tabular}

Table 1: Social interaction with leadership competencies and attributes across each of the three groups.

RQ2 asked if there was a relationship between social interaction and job embeddedness across the three different groups. The data from the correlational analysis are found in Table 2. The findings suggested a significant positive relationship between social interaction and job embeddedness across each of the three workgroups [22].

RQ3 asked if a relationship exists between the leadership competencies and attributes and job embeddedness. Twelve hypotheses were tested. The results are found in Table 3. The findings suggested a significant positive relationship between self-awareness, relational transparency, internal moral perspective, balanced processing, and job embeddedness across each of the three work groups [22].

\begin{tabular}{|l|c|c|c|c|c|c|}
\hline & Face-to Face & \multicolumn{2}{c|}{ Hybrid } & \multicolumn{2}{c|}{ Virtual } \\
\hline & $\boldsymbol{r}$ & $\rho$ & $\boldsymbol{r}$ & $\rho$ & $\boldsymbol{r}$ & $\rho$ \\
\hline $\begin{array}{l}\text { Job } \\
\text { Embeddedness }\end{array}$ & $.426^{* *}$ & $.371^{* *}$ & $.539^{* *}$ & $.504^{* *}$ & $.651^{* *}$ & $.623^{* *}$ \\
\hline $\begin{array}{l}\text { Notes: ** Correlation is significant at } .01(2 \text { tailed); } \mathrm{df}=302 \text {; Face-to-Face }-\mathrm{N} \\
=115, \text { Hybrid }-\mathrm{N}=101 \text {, Virtual }-\mathrm{N}=88 .\end{array}$ \\
\hline
\end{tabular}

Table 2: Social interaction with job embeddedness across each of the three groups. 
RQ4, RQ5, and RQ6 examined the difference between the different groups, face-to-face, hybrid, and virtual, in relation to leadership competencies and attributes, social interaction, and job embeddedness. To avoid potential Type 1 errors, Tabachnick and Fidell [24] suggested using a series of ANOVAs over a MANOVA when Pearson $r$ correlation values are .6 or below.

\begin{tabular}{|l|c|c|c|c|c|c|}
\hline & Face-to Face & \multicolumn{2}{c|}{ Hybrid } & \multicolumn{2}{c|}{ Virtual } \\
\hline & $\boldsymbol{r}$ & rho & $\boldsymbol{r}$ & rho & $\boldsymbol{r}$ & rho \\
\hline $\begin{array}{l}\text { Self- } \\
\text { Awareness }\end{array}$ & $.447^{* *}$ & $.411^{* *}$ & $.529^{* *}$ & $.462^{* *}$ & $.542^{* *}$ & $.486^{* *}$ \\
\hline $\begin{array}{l}\text { Relational } \\
\text { Transparency }\end{array}$ & $.411^{* *}$ & $.371^{* *}$ & $.299^{* *}$ & $.295^{* *}$ & $.549^{* *}$ & $.504^{* *}$ \\
\hline $\begin{array}{l}\text { Internal } \\
\text { Moral } \\
\text { Perspective }\end{array}$ & $.400^{* *}$ & $.408^{* *}$ & $.549^{* *}$ & $.420^{* *}$ & $.592^{* *}$ & $.564^{* *}$ \\
\hline $\begin{array}{l}\text { Balanced } \\
\text { Processing }\end{array}$ & $.413^{* *}$ & $.380^{* *}$ & $.489^{* *}$ & $.428^{* *}$ & $.489^{* *}$ & $.433^{* *}$ \\
\hline $\begin{array}{l}\text { Notes: ** Correlation is significant at } .01(2 \text { tailed); } \mathrm{df}=302 ; \text { Face-to-Face }- \\
\mathrm{N}=115 \text {, Hybrid }-\mathrm{N}=101 \text {, Virtual }-\mathrm{N}=88 .\end{array}$ \\
\hline
\end{tabular}

Table 3: Leadership competencies and attributes with job embeddedness across each of the three groups.

Table 4 displays the data from the leadership competencies and attributes subscale Pearson $r$ correlation. Therefore, a series of ANOVAs were used to address RQ4, RQ5, and RQ6. RQ4 asked if differences existed between the three groups and in relationship to leadership competencies and attributes. Four hypotheses were tested. The results are displayed in Table 5. The findings suggested there is no significant differences between the three groups in relation to leadership competencies [22].

\begin{tabular}{|l|c|c|c|c|}
\hline & SA & RT & MP & BP \\
\hline $\begin{array}{l}\text { Self- Awareness } \\
\text { (SA) }\end{array}$ & & $.771^{* *}$ & $.745^{* *}$ & $.839^{* *}$ \\
\hline $\begin{array}{l}\text { Relational } \\
\text { Transparency (RT) }\end{array}$ & $.771^{* *}$ & & $.721^{* *}$ & $.724 * *$ \\
\hline $\begin{array}{l}\text { Internal Moral } \\
\text { Perspective (MP) }\end{array}$ & $.745^{* *}$ & $.721^{* *}$ & & $.736^{* *}$ \\
\hline $\begin{array}{l}\text { Balanced Processing } \\
\text { (BP) }\end{array}$ & $.839^{* *}$ & $.724 * *$ & $.736^{* *}$ & \\
\hline \multicolumn{2}{|l|}{ Note: ** Correlation is significant at .01 (2 tailed); df $=302 ; \mathrm{N}=304$} \\
\hline
\end{tabular}

Table 4: Leadership competencies and attributes subscales correlations.

\begin{tabular}{|l|c|c|}
\hline & \multicolumn{2}{|c|}{ ANOVA } \\
\hline & F & sig \\
\hline Self- Awareness & .461 & .631 \\
\hline Relational Transparency & .267 & .766 \\
\hline Internal Moral Perspective & 1.542 & .216 \\
\hline Balanced Processing & .201 & .818 \\
\hline Notes: Difference is significant below.05: Face-to-Face - N = 115, Hybrid - N \\
\multicolumn{2}{|c|}{$=101$, Virtual - N = 88. } \\
\hline
\end{tabular}

Table 5: Differences between groups and the social interaction.

RQ5 asked if there were difference between the three groups in relation to social interaction. Four hypotheses were tested. The results are displayed in Table 6 . The analysis suggested no significant different between groups in relation to social interaction [22].

\begin{tabular}{|l|c|c|}
\hline & \multicolumn{2}{|c|}{ ANOVA } \\
\hline & F & sig \\
\hline Social Interaction & .213 & .808 \\
\hline Notes: Difference is significant below.05: Face-to-Face $-\mathrm{N}=115$, Hybrid $-\mathrm{N}$ \\
$=101$, Virtual $-\mathrm{N}=88$.
\end{tabular}

Table 6: Differences between groups and social interaction.

RQ6 examined the difference between the three groups in relation to job embeddedness. Four hypotheses were tested. The results are displayed in Table 7 . The findings suggested no significant difference between the three groups and the level of job embeddedness [22].

\begin{tabular}{|l|c|c|}
\hline & \multicolumn{2}{|c|}{ ANOVA } \\
\hline & F & sig \\
\hline Job Embeddedness & .865 & .422 \\
\hline Notes: Difference is significant below.05: Face-to-Face $-\mathrm{N}=115$, Hybrid $-\mathrm{N}$ \\
\multicolumn{2}{|c|}{$=101$, Virtual $-\mathrm{N}=88}$. \\
\hline
\end{tabular}

Table 7: Differences between groups and job embeddedness.

RQ7 asked, when taken together, which of the leadership competencies and attributes along with social interaction, are the most significant predictors of job embeddedness? The analysis included a reverse stepwise regression. A Pearson $r$ correlation was conducted to ensure no independent variables correlated above 9 [24]. The data is displayed in Table 8 .

\begin{tabular}{|l|c|c|c|c|c|}
\hline & SA & RT & MP & BP & SI \\
\hline $\begin{array}{l}\text { Self- Awareness } \\
\text { (SA) }\end{array}$ & & $.771^{* *}$ & $.745^{* *}$ & $.839^{* *}$ & $.801^{* *}$ \\
\hline $\begin{array}{l}\text { Relational } \\
\text { Transparency } \\
\text { (RT) }\end{array}$ & $.771^{* *}$ & & $.721^{* *}$ & $.724^{* *}$ & $.771^{* *}$ \\
\hline $\begin{array}{l}\text { Internal Moral } \\
\text { Perspective } \\
\text { (MP) }\end{array}$ & $.745^{* *}$ & $.721^{* *}$ & & $.736^{* *}$ & $.739^{* *}$ \\
\hline $\begin{array}{l}\text { Balanced } \\
\text { Processing (BP) }\end{array}$ & $.839^{* *}$ & $.724^{* *}$ & $.736^{* *}$ & & $.778^{* *}$ \\
\hline $\begin{array}{l}\text { Social } \\
\text { Interaction (SI) }\end{array}$ & $.801^{* *}$ & $.771^{* *}$ & $.739^{* *}$ & $.778^{* *}$ & \\
\hline \multicolumn{7}{|l|}{ Note: ** Correlation is significant at .01 (2 tailed); df $=302 ; \mathrm{N}=304$} \\
\hline
\end{tabular}

Table 8: Independent variable correlations.

Five data points were identified as potential outliers, with standardized scores larger than 3.29 or less than -3.29 [24]. The outlier data is displayed in Table 9. The outliers were not deleted or transformed as a few outliers are expected in large sample sizes and do not negatively influence the results [24]. One hypothesis was tested [22].

The reverse stepwise regression was conducted to model the predictability of job embeddedness from the variables, selfawareness, relational transparency, internal moral perspective, balanced processing, and social interaction. Overall, the regression was significant, $F(2,301)=71.00, p<.05, \mathrm{R}^{2}=.32$. Of the predictors investigated, both internal moral perspective $(\beta=.27, t(301)=3.86), p<.05$ and social interaction $(\beta=.34$, $t(301)=4.75), p<.05$ were significant predictors of job embeddedness. Self-awareness $(\beta=.10, t(300)=1.28), p>$ .05 , relational transparency $(\beta=-.14, t(299)=-1.40), p>.05$, and balanced processing $(\beta=-.07, t(298)=-.71), p>.05$ were not significant predictors of job embeddedness. 


\begin{tabular}{|l|c|c|c|}
\hline Participant & Group & Subscale & Z Score \\
\hline 122 & Face-to-face & Social Interaction & -3.312 \\
\hline 137 & Virtual & Relational Transparency & -3.640 \\
\hline 137 & Virtual & Internal Moral Perspective & -3.341 \\
\hline 158 & Hybrid & Social Interaction & -3.400 \\
\hline 251 & Virtual & Internal Moral Perspective & -3.341 \\
\hline \multicolumn{3}{|c|}{ Note: All other participant responses were above -3.29. } \\
\hline
\end{tabular}

Table 9: Outlier data.

An $80 \%$ - $20 \%$ cross-validation analysis was completed to test for overfitting. The results are displayed in Table 10.

The large positive correlation, along with the proximity of the two Pearson $r$ correlations indicated an adequate fitting model. The reverse stepwise regression data are displayed in Table 11.

\begin{tabular}{|l|c|c|c|}
\hline Analysis & $\boldsymbol{R}^{2}$ & Pearson $\boldsymbol{r}$ & Sig. \\
\hline $80 \%$ Population & .33 & $.524^{* *}$ & .000 \\
\hline $20 \%$ Population & .31 & $.579^{* *}$ & .000 \\
\hline \multicolumn{2}{|c|}{ Note: ** Significant at .01 (2 tailed): $80 \%$ Population $-\mathrm{n}=255,20 \%$} \\
Population $-\mathrm{n}=49$. \\
\hline
\end{tabular}

Table 10: Reverse stepwise regression cross validation.

\begin{tabular}{|c|c|c|c|c|c|}
\hline Group & $\mathbf{N}$ & Predictors & $\mathbf{R}^{2}$ & $\boldsymbol{\beta}$ & Sig. \\
\hline $\begin{array}{c}\text { Face-to- } \\
\text { Face }\end{array}$ & 115 & Self-Awareness & .20 & .40 & .000 \\
\hline Hybrid & 101 & Self-Awareness & .41 & -.436 & .033 \\
\hline & & Relational Transparency & & .378 & .006 \\
\hline & & Internal Moral Perspective & & .283 & .004 \\
\hline & & Social Interaction & & .283 & .034 \\
\hline Virtual & 88 & Social Interaction & .42 & .325 & .000 \\
\hline
\end{tabular}

Table 11: Reverse stepwise regression by group.

A review of the data prompted an ancillary question not planned in the original study [22]. Given the regression model to predict job embeddedness across the entire sample, is the predictive model for job embeddedness the same for each of the individual groups, face-to-face, hybrid, and virtual? A reverse stepwise regression was conducted predicting job embeddedness from the variables self-awareness, relational transparency, internal moral perspective, balance processing, and social interaction for each of the three work environments, face-to-face, hybrid, and virtual. The sample sizes did not meet Pallant [25] or Tabachnick and Fidell's [24] recommendation of 40 samples for each dependent variable, which also did not allow for cross-validation.

Each regression was significant and identified different predictors for each group. Of the predictors investigated for the face-to-face group, $F(1,113)=28, p<.05, \mathrm{R}^{2}=.20$, selfawareness $(\beta=.40, t(113)=5.32, p<.05)$ was a significant predictor of job embeddedness. Relational transparency $(\beta=$ $.07, t(113)=.39, p>.05)$, internal moral perspective $(\beta=.19$, $t(113)=1.31, p>.05)$, balanced processing $(\beta=-.01, t(113)=$ $-.07, p>.05)$, and social interaction $(\beta=.07, t(113)=1.00, p>$ $.05)$ were not significant predictors of job embeddedness.
The $\mathrm{R}^{2}$ suggested the predictors accounted for $20 \%$ of the variance in the job embeddedness scores within the co-located environment. Of the predictors investigated for the hybrid group, $F(4,96)=16.59, p<.05, \mathrm{R}^{2}=.41$, self-awareness $(\beta=$ $.28, t(96)=2.17, p<.05)$, relational transparency $(\beta=-.44$, $t(96)=-2.81, p<.05)$, internal moral perspective $(\beta=.38$, $t(96)=2.97, p<.05)$, and social interaction $(\beta=.15, t(96)=$ $2.16, p<.05)$ were significant predictors of job embeddedness, while balanced processing $(\beta=.01, t(96)=.07, p>.05)$ was not a significant predictor of job embeddedness. The predictors accounted for $41 \%$ of the variance in the job embeddedness scores within the mixed environment. Of the predictors investigated for the virtual group, $F(1,86)=63.32, p$ $<.05, \mathrm{R}^{2}=.42$, social interaction $(\beta=.33, t(86)=7.96, p<$ $.05)$ was a significant predictor of job embeddedness. Selfawareness $(\beta=.02, t(86)=.11, p>.05)$, relational transparency $(\beta=-.00, t(86)=-.02, p>.05)$, internal moral perspective $(\beta=.15, t(86)=1.05, p>.05)$, and balanced processing $(\beta=-.17, t(86)=-1.20, p>.05)$ were not significant predictors of job embeddedness. The predictors accounted for $42 \%$ of the variance in the job embeddedness scores within the virtual environment.

The results of the hybrid work environment may suggest that a combination of face-to-face and remote workers creates a unique perspective. When workers experience face-to-face and remote work environments, the leadership competencies and attributes increase. This may also point to the complexity of the fluid flexible workplace. Additional research is warranted to further understand these differences in the hybrid environment.

\section{DISCUSSION \& CONCLUSION}

Twenty-first century organizations face the challenge of developing leaders with the KSAs required to balance the needs of the organization with worker demands for flexibility. The great resignation identified by Klotz [1] demonstrates the resolute of workers to no longer conform to the nine-to-five in-office work environment. The demand for high quality talent, technology-mediated tools to support online collaboration, and a pent-up worker desire to live life differently, organizations are forced to examine not only traditional workplace models but also existing leadership models.

The research conducted by Figaro [8] and Hopkins [22] demonstrated that leadership in hybrid and virtual workplace models require broader KSAs. While century's long research has primarily focused on leadership in a conventional environment, that is, when employees can be seen or face-toface, leadership in a virtual environment has been vastly underexplored. The presupposition that conventional leadership theory translates in a virtual environment has resulted in less than successful WFH strategies for many organizations and has contributed to the outcry of the great resignation.

While similarities between conventional leadership and virtual team leadership [8] extended research conducted by Hertel, et 
al. [11] on virtual team members to identify what competencies and attributes and KSAs were also necessary for the Virtual Team Leader (VTL). Because many organizations currently have the means of measuring talent acquisition and performance criterion for both individuals and teams, the notion of measuring specific KSAs is not holistically a novel concept and past research on conventional teams has provided a promising foundation when evaluating virtual teams. However, little research has provided a means to assess talent acquisition in a virtual environment and little to no data exists on what competencies, attributes, or KSAs are both relevant and needed by the VTL [8].

Assembling a Delphi panel of 40 experts to explore what competencies and attributes of virtual team members were also pertinent to VTLs, Figaro [8] found that while many of the competencies and attributes and KSAs established for the virtual team were relevant to the VTL, there were additional KSAs that were critical to the success of the VTL in a virtual environment. The competencies and attributes, and KSAs resulting from Figaro's results are listed in Table 12.

Figaro's [8] research suggested that leadership in a virtual environment is not only relegated to the specific attributes, that is who one is, and competencies - what one does, but also, may require the amplified ability to communicate, an increased ability to communicate interdependently, increased organizational skills, analytical ability and most critically cognitive ability.

\begin{tabular}{|c|c|c|c|}
\hline $\begin{array}{l}\text { VTCI (Virtual Team } \\
\text { Members) [11] }\end{array}$ & & $\begin{array}{l}\text { Virtual Team Leader (VTL) } \\
\text { Competencies and Attributes } \\
{[8]}\end{array}$ & \\
\hline Conscientiousness & 4 & Conscientiousness & 5 \\
\hline Integrity & 4 & Integrity & 7 \\
\hline Loyalty & 3 & Loyalty & 3 \\
\hline Cooperativeness & 4 & Cooperativeness & 4 \\
\hline Communication Skills & 4 & Communication Skills & 12 \\
\hline Persistence & 3 & Persistence & 6 \\
\hline Willingness to Learn* & 3 & Cognitive Ability** & 20 \\
\hline Creativity & 4 & Creativity & 3 \\
\hline Independence & 3 & Independence & 2 \\
\hline Interpersonal Trust & 3 & Interpersonal Trust & 5 \\
\hline \multirow[t]{3}{*}{ Intercultural Skills* } & 4 & $\begin{array}{l}\text { Interdependent } \\
\text { Communication** }\end{array}$ & 4 \\
\hline & & Organizational Skills** & 4 \\
\hline & & Analytical Ability** & 5 \\
\hline Total KSA Items & 39 & & 80 \\
\hline \multicolumn{2}{|c|}{$\begin{array}{l}\text { Note. *Omitted Subscales due to } \\
\text { due to dropped VTCI items. }\end{array}$} & $\begin{array}{l}\text { **Possible New VTL subscales } \\
\text { (Figaro, 2015) }\end{array}$ & \\
\hline
\end{tabular}

Table 12: Competencies and attributes for VTLs.

Figaro [8] suggested cognitive ability should be explored further to understand whether cognitive ability is inherent to the individual such as IQ or if this is an area that can be learned. Additionally, while 50.1\% of the panel in Figaro's [8] study believed the competencies and attributes could be taught, the panel believed that only $62.2 \%$ of the competencies and attributes could be taught.

Because research suggested differing levels of KSAs are needed in different environments, research should focus on what specific KSAs can be learned. For many organizations, the great resignation coupled with a decreasing pool of qualified knowledge workers to fill the vacant roles may result in shrinking revenue, market share, innovation, and the ability to compete globally [8].

The pandemic has disrupted the workplace in ways most never imagined. Global complexity has increased the high stakes deliverables that require continuous creativity and innovation. While organizations and workers demonstrated tremendous resilience and flexibility during the pandemic, workers now demand a future workplace that provides greater flexibility. Leadership KSA's must expand to advance relationships that contribute to attracting and retaining qualified employees and engaging them in innovative, collaborative teamwork [26].

Leaders and workers in virtual and hybrid environments face more significant challenges than those in traditional face-toface workplaces [8, 9, 22, 27-29]. Communication goes beyond sharing words, written or verbal, but is a "sharing of elements of behavior and modes of life", and is essentially a social affair [30]. This "social interaction is the very essence of being human.... and extremely powerful in building empathy and trust between people" [21].

The research conducted by Pentland [19], Waber [20], and Waber, suggested social interaction, those subsidiary conversations that take place in the workplace, are critical to building trusting relationships that yield higher productivity, creativity, and innovation. In virtual environments, accidental conversations no longer exist; each encounter requires intentionality. The need for communication skills is "amplified in virtual environments" [8]. The number one factor in effective work teams is the ability to communicate on a deeper personal level [21].

In a post pandemic environment, organizational leaders clamor to develop hybrid and virtual work models that balance the needs of the organization and expectations of a determined mobile workforce. Leaders with strong KSAs that support the development of collaborative team members, who may be dispersed in a local community or around the globe with little opportunity for face-to-face interaction, create work teams that exhibit greater productivity, creativity, and innovation $[8,19$, 20]. Leadership has a direct influence on positive social interaction with and between team members [31], and the most significant influencers on team member retention include internal team member relationships $[22,32]$.

Considering the great resignation occurring in the U.S., organizational leaders scramble to curb the mass exodus of valuable talent. The research by Mitchell, et al. [16] suggested that understanding job embeddedness, the array of on and off- 
the-job connections that link an individual to an organization, is crucial to talent retention. Retaining post pandemic workers go beyond pay, benefits, and job satisfaction to include flexibility and a belief that leaders will work to balance individual and organizational needs, thus positively influencing the level of worker job embeddedness [22]. A virtual team member's level of embeddedness, their intention to stay with an organization, is most influenced by the leader's moral character and their ability to drive social interaction [22]. Figaro [8] arrived at a very similar conclusion with the resulting amplification of integrity and communication, as virtual team leadership KSAs.

The research by Hopkins [22] suggested that social interaction was a significant predictor of worker job embeddedness with workers in hybrid and virtual environments. Raising the question, how do leaders create hybrid and virtual work environments that encourage and promote social interactions where accidental exchanges no longer exist? How do leaders create intentional interactions to replace those that once took place naturally and organically in the workplace? Figaro's [8] results demonstrating the criticality of the communication KSA in hybrid and virtual environments suggests leaders in those workplaces examine and develop broader communication skills.

As organizations plan for the return of workers to the workplace and navigate the great resignation, leaders need to examine communication skills, seek to create opportunities for social interaction, and look beyond traditional worker retention models to include both on and off-the-job influences that drive job embeddedness.

Additional research is needed to understand the nuances of managing those that are in-person, those that work remote, and those that have a desire for both. Future research should investigate productivity measures and the incorporation of deliverables. Additional instruments are needed to facilitate identification along with measures for leadership KSAs that support recruiting and retention of workers in hybrid and remote work environments. Finally, as criteria for leadership success in such fluid environments continues to evolve, a deeper understanding of the cultural diversity influences on social interaction and the development of trusting relationships is needed.

\section{REFERENCES}

[1] Klotz, A. (2021). Anthony Klotz on defining the great resignation. The Verse.

[2] Williamson, K. D. (2021). The Great Resignation. National Review.

[3] Thompson, C. (2020). What if working from home goes on forever? New York Times Magazine.

[4] Kelly, J. (2021). Why the great resignation is greatly exaggerated? Forbes.

[5] Homegardner, T. (2021). What is the great resignation and how will it affect job seekers? Forbes.

[6] Haounji, J. (2021). The great resignation and the future of the workplace. Entrepreneur Middle East.
[7] Gandhi, V., \& Robison, J. (2021). The 'great resignation' is really a 'great discontent.' Gallup.

[8] Figaro, K. (2015). Competencies and attributes essential for 21st century virtual team leadership: A Delphi study. (Doctoral dissertation). Retrieved from ProQuest Dissertations \& Theses Global. (UMI No. 3729004).

[9] Lipnack, J., \& Stamps, J. (2000). Virtual teams: People working across boundaries with technology. New York, NY: John Wiley \& Sons.

[10] Potter, E. E. (2003). Telecommuting: The future of work, corporate culture, and American society. Journal of Labor Research, 24(1), 73-84.

[11] Hertel, G., Konradt, U., \& Voss, K. (2006). Competencies for virtual teamwork: Development and validation of a web-based selection tool for members of distributed teams. European Journal of Work \& Organizational Psychology, 15(4), 477-504.

[12] Barrero, J. M., Bloom, N., \& Davis, S. J. (2021). Don't force people to come back to the office full time.

[13] Griffis, H. (March). What is a hybrid work model, and how do we make it work. BuiltIn.

[14] Hertel, G., Geister, S., \& Konradt, U. (2005). Managing virtual teams: A review of current empirical research. Human Resource Management Review, 15(1), 69-95.

[15] Lahti, M. and Nenonen, S. (2021). Design science and codesigning of hybrid workplaces. Buildings, 11(3), 129-135.

[16] Mitchell, T. R., Holtom, B. C., Lee, T. W., Sablynski, C. J., \& Erez, M. (2001). Why people stay: Using job embeddedness to predict voluntary turnover. Academy of Management Journal, 44(6), 1102-1121.

[17] Porter, L. W., Steers, R. M., Mowday, R. T., \& Boulian, P. V. (1974). Organizational commitment, job satisfaction, and turnover among psychiatric technicians. Journal of Applied Psychology, 59(5), 603-609.

[18] Dawley, D. D., \& Andrews, M. C. (2012). Staying put: Off-thejob embeddedness as a moderator of the relationship between on-the-job embeddedness and turnover intentions. Journal of Leadership \& Organizational Studies, 19(4), 477-485.

[19] Pentland, A. (2014). Social physics: How good ideas spread-the lessons from a new science. New York, NY: The Penguin Press.

[20] Waber, B. (2013). People analytics: How social sensing technology will transform business and what it tells us about the future of work. Upper Saddle River, NJ: Pearson Education.

[21] Colvin, G. (2015). Humans are underrated: What high achievers know that brilliant machines never will. New York, NY: Penguin Random House, LLC.

[22] Hopkins, J. (2019). The impact of leadership on member social interaction and embeddedness in virtual environments. (Doctoral dissertation). ProQuest Dissertations and Thesis Global. (UMI No. 27664758).

[23] Cohen, J. (1992). A power primer. Psychological Bulletin, $112(1), 155-159$.

[24] Tabachnick, B. G., \& Fidell, L. S. (2019). Using multivariate statistics (7th ed.). Boston, MA: Pearson Education.

[25] Pallant, J. (2016). SPSS survival manual (6th ed.). New York, NY: Open University Press.

[26] Meister, J. C., \& Mulcahy, K. J. (2017). The future workplace experience: 10 rules for mastering disruption in recruiting and engaging employees. New York, NY: McGraw-Hill Education. 
[27] Ferrell, J., \& Kline, K. (2018). Facilitating trust and communication in virtual teams. People and Strategy, 4(2), 3035 .

[28] Gibson, C. B., \& Manuel, J. A. (2003). Building trust: Effective multicultural communication processes in virtual teams. In C. B. Gibson \& S. G. Cohen (Eds.), Virtual teams that work: Creating conditions for virtual team effectiveness (pp. 59-86). San Francisco, CA: Jossey-Bass.

[29] Owens, D., \& Khazanchi, D. (2018). Exploring the impact of technology capabilities on trust in virtual teams. American Journal of Business, 33(4), 157-178.
[30] Cherry, C. (1961). On Human Communication. New York, NY: Science Editions Inc.

[31] Avolio, B. J., \& Gardner, W. L. (2005). Authentic leadership development: Getting to the root of positive forms of leadership. The Leadership Quarterly, 16(3), 315-338.

[32] Chen, J. R., Chou, T. C., \& Wang, T. W. (2010). The organizational context, job embeddedness, and effectiveness of managing knowledge work teams. Journal of Applied Business Research, 26(5), 19-27.

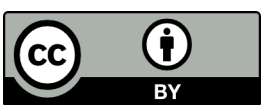

(C) 2021 by the Dr. Joseph C. Hopkins and Dr. Kimberly A. Figaro. Submitted for possible open access publication under the terms and conditions of the Creative Commons Attribution (CC BY) license (http://creativecommons.org/licenses/by/4.0/). 